\section{An unusual case of Lyme borreliosis: Can we miss it?}

\author{
Antigona Begolli Gerqari, ${ }^{1}$ \\ Mybera Ferizi, ${ }^{1}$ Sadije Halimi, ${ }^{1}$ \\ Albina Ponosheci, ${ }^{2}$ Arjeta Zogaj Berisha, ${ }^{2}$ \\ Idriz Gerqari ${ }^{3}$ \\ ${ }^{1}$ Dermatology Clinic, University Clinical \\ Center of Kosovo, Prishtina; \\ ${ }^{2}$ Infectiology Clinic, University Clinical \\ Center of Kosovo, Prishtina; \\ ${ }^{3}$ Department of Nuclear Medicine, \\ University Clinical Center of Kosovo, \\ Prishtina, Kosovo
}

\begin{abstract}
Lyme borreliosis is an infective disease that is usually transmitted to humans via biting by bacteria-infected Ixodes tick. The disease is multisystemic and the affected organs are the skin (Erythema migrans), nervous system, eyes, heart and joints. Borrelia burgdorferi is the bacterium that causes borreliosis and the hosts are rodents of the genus Apodemus. In the Balkan region, Ixodes ricinus is the most representative vector. A bite from an infected insect is the most common mode of transmitting Borrelia; however, transplacental transmission has also been documented. Pathogenesis of the disease consists of both direct and indirect mechanisms of immunological reactions which result in the production of $\operatorname{IgM}$ antibodies to Borrelia in the first 3-6 weeks, and production of IgG class after 6 weeks. Many skin diseases and skin symptoms mimicking Lyme borreliosis, such as dermatomycosis, erysipelas, and undefined hyperpigmentation must be elaborated and considered for borreliosis, as skin symptoms of borreliosis can imitate many of them.
\end{abstract}

\section{Introduction}

Lyme borreliosis is a disease in which the spirochete Borrelia burgdorferi causes three main skin changes: i) erythema chronicum migrans, ii) borrelial lymphocytoma, and iii) acrodermatitis chronic atrophicans..$^{1-3}$ The bacterium which causes the disease is found in rats and other rodents. The main vector of Lyme borreliosis is Ixodes ricinus, mainly transmitting disease in Europe, while in Asia Ixodes persulcatus is the main vector. Lyme borreliosis is classified in three stages: first stage with skin symptoms, second stage with erythema chronicum migrans and lymphocytoma cutis and third stage with an involvement of the central nervous system, cardiovascular system, kidneys and joints. ${ }^{1,4}$ Here we present a very unusual case of borreliosis with skin changes in the lower abdominal region, specifically located in the suprapubic region in a clothing-covered area. The patient was unaware of any tick bite or exposure; she lives in an urban area and works in medical profession.

\section{Case Report}

A 35-year-old woman, nurse by profession, presented in our ambulant patient unit complaining about a skin problem located in the suprapubic region. The typical sign was an erythematous patch with scaling and crusting (Figure 1), and subjective symptoms like itching and burning. During the last few days the patient had treated the skin patch with an antimycotic cream, but the problem persisted and fever and myalgia accompanied the condition. The patient self-administered an antipyretic, explaining that she thought it was just a flu. By then the general practitioner referred the patient to a dermatologist. The native conventional microscopy with an addition of $20 \% \mathrm{KOH}$ (Potassium hydroxide) indicated mycosis showing the group of spores, although there were very unspecific signs and the patient denied that she was ticked by an insect, particularly as she did not live in an area where Borrelia is endemic. We carried out the serological analyses for $B$. burgdorferi.

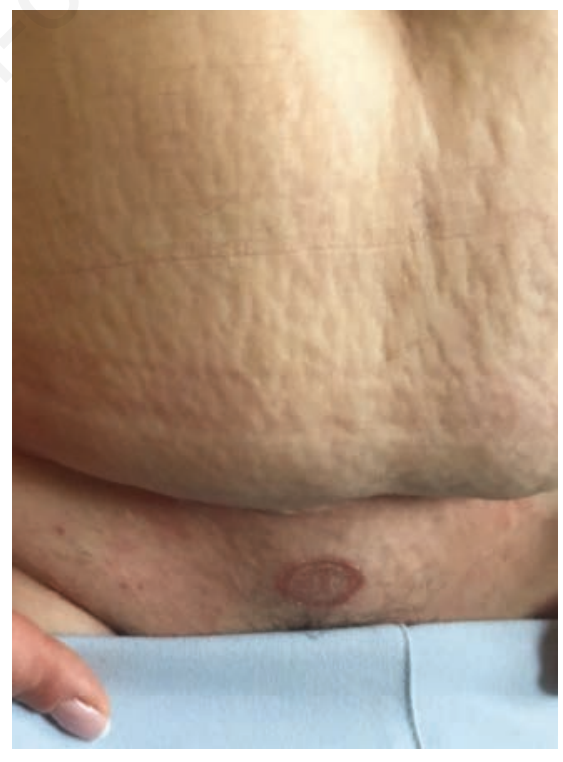

Figure 1. Atypical skin lesion caused by borreliosis and located on the suprapubic region.
Correspondence: Antigona Begolli Gerqari, Dermatology Clinic, University Clinical Center of Kosovo, Mother Teresa str, nn, Prishtina, 10000, Republic of Kosovo.

E-mail: antigonagerqari@gmail.com

Key words: Lyme borreliosis; Erythema migrans; Ixodes ticks.

Conflict of interest: the authors declare no potential conflict of interest.

Funding: none.

Received for publication: 7 February 2019. Revision received: 23 March 2019.

Accepted for publication: 23 March 2019.

This work is licensed under a Creative Commons Attribution-NonCommercial 4.0 International License (CC BY-NC 4.0).

C Copyright: the Author(s), 2019

Licensee PAGEPress, Italy

Dermatology Reports 2019; 11:8021

doi:10.4081/dr.2019.8021

Three days later we obtained the following results: IgG antibody test for $B$. burgdorferi 0.120 (negative under the reference range of $\max 0.334$ ) and IgM positive 1.562 (reference range under 0.610). The patient was immediately prescribed the following antibiotic therapy of amoxicillin $500 \mathrm{mg}$ every 6 hours for 4 weeks. The ultrasound of abdomen was performed, and consultation with neurologist, cardiologist, ophthalmologist and rheumatologist revealed that there were no pathological signs of visceral

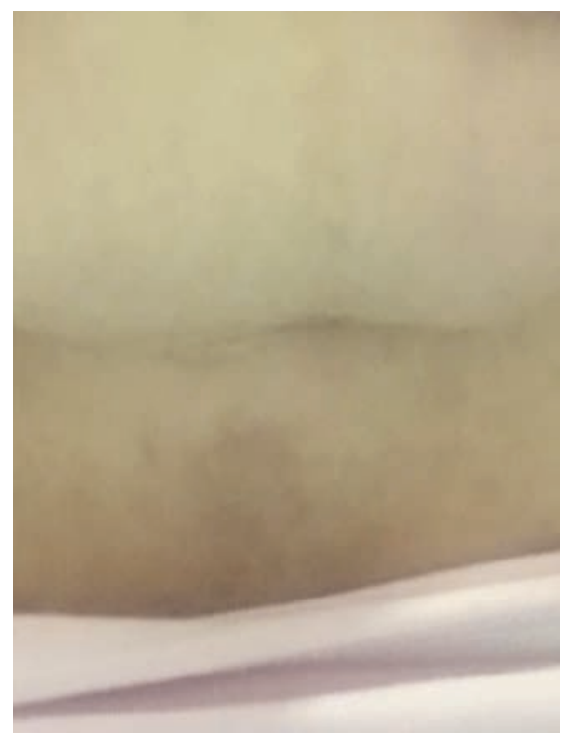

Figure 2. Clearing of the lesion following the treatment for borreliosis. 
involvement. We repeated the serological tests after one month and the results showed same level of the $\operatorname{IgG}$ antibodies and a decrease in level of the IgM for Borrelia. The patient was advised to repeat the serological test after three months and during that period there were no more subjective symptoms, accompanied with clearing of the skin lesions (Figure 2). Furthermore, there was no increase in levels of antibodies specific for B. burgdorferi.

\section{Discussion and Conclusions}

B. burgdorferi is a bacterium that can affect the tissues of many organs. The bacteria disseminate in the skin, and skin reacts with numerous skin changes that sometimes are in a discrepancy with a number of spirochetes, that is generally explained with an aggressive response of the host to an invasion of Borrelia. The clinical manifestation of borreliosis in the skin is very different. ${ }^{5}$ Due to this fact the diagnosis of infection with $B$. burgdorferi can often be missed by doctors. Skin manifestations are early signs of Lyme disease, ${ }^{6,7}$ and detecting the disease early can prevent the affection of visceral organs and joints. ${ }^{1}$ The early signs of the disease are related to other viral or bacterial infections including fever, myalgia, and headache, followed by skin changes. It is very important to elaborate the skin symptoms which are very similar to mycotic disease, hyperpigmentation and atrophy of the skin, erythema annulare centrifugum, erythema gyratum repens, fixed drug eruptions, contact dermatitis and erysipelas. Some diseases like morphea, lichen sclerosus, ${ }^{8}$ and Atrophoderma of Pasini and Pierini must be evaluated for Borrelia, because Borrelia infection may be the underlying disease. ${ }^{8}$ The undiagnosed borreliosis may lead to a chronic form of the disease that is manifested with vital organ involvements including neurological manifestation, meningitis and neuropathy, myocarditis, kidney problems and arthropathy. The role, duty and responsibility of the dermatologist are to address the doubts in the disease, especially when patients come from endemic areas, even when they deny the tick bite or when skin signs are not as characteristic as those presented and described in our case. It is therefore essential not to rule out Lyme disease in individuals presenting with characteristic symptoms even in absence of history of tick bites or exposure.

\section{References}

1. Steere AC, Malawista SE, Hardin JA, et al. Erythema chronicum migrans and Lyme arthritis. The enlarging clinical spectrum. Ann Intern Med 1977;86:685-98.

2. Strle F, Pleterski-Rigler D, Stanek G, et al. Solitary borrelial lymphocytoma: report of 36 cases. Infection 1992;20:201-6.

3. Asbrink E, Hovmark A. Successful cultivation of spirochetes from skin lesions of patients with erythema chronicum migrans Afzelius and acrodermatitis chronica atrophicans. Acta Pathol Microbiol Immunol Scand B 1985;93:161-3.

4. Nardelli DT, Callister SM, Schell RF. Lyme arthritis: Current concepts and a change in paradigm. Clin Vaccine Immunol 2008;15:21-34.

5. Wu YS, Zhang WF, Feng FP, et al. Atypical cutaneous lesions of Lyme disease. Clin Exp Dermatol 1993;18:4346.

6. Berger BW. Dermatologic manifestations of Lyme disease. Rev Infect Dis 1989;11:S1475-81.

7. Malane MS, Grant-Kels JM, Feder HM, Luger SW. Diagnosis of Lyme disease based on dermatologic manifestations. Ann Intern Med 1991;114:490-8.

8. Ozkan S, Atabey N, Fetil E, et al. Evidence for Borrelia burgdorferi in morphea and lichen sclerosus. Int $\mathrm{J}$ Dermatol 2000;39:278-83. 